\title{
EFEITOS DA TRANSFERÊNCIA DETECNOLOGIA DE UNIVERSIDADES NORTE AMERICANA E BRASILEIRA NO CAPITAL HUMANO TÉCNICO E CIENTÍFICO
}

\section{Effects of Technology Transfer from American and Brazilian Universities on the Scientific and Technical Human Capital}

\section{Daniela Althoff Philippi}

Doutora em Administração pela Universidade Nove de Julho (UNINOVE). Professora Adjunta da Universidade Federal de Mato Grosso do Sul (UFMS). Cuiabá, MS. Brasil.

e-mail:daniela.philippi@ufms.br

\section{Emerson Antonio Maccari}

Doutor em Administração pela USP (2008) com Estágio Doutoral na University of Massachusetts Amherst (USA). Diretor e Professor do Programa de Pós-Graduação em Administração (PPGA - UNINOVE). São Paulo, SP. Brasil.e-mail: emersonmaccari@gmail.com

\section{RESUMO}

A Transferência de Tecnologia Universidade-Empresas (TTU-E) é adotada como estratégia de inovação aberta. Destaca-se o de Eficácia Contingente, que possibilita a descrição de TTs e seus efeitos, como no capital humano, técnico e científico. Contudo, a cultivar, um dos meios de TT de grande valor social e econômico, não é citada no modelo. O objetivo da pesquisa foi verificar os efeitos no capital humano, técnico e científico de processos de TT-UE de cultivares no Brasil e nos EUA. Adotou-se o estudo multi-casos, com pesquisa documental e entrevistas com agentes (universidades) e receptores (organizações) no segundo semestre de 2014, e análise cruzada. Revelaram-se diferenças nos contextos nacionais de inovação e que o estudo do capital humano técnico e científico deve se estender à criação de redes de conhecimento e à habilidade de comunicação entre academia e organizações, contribuindo, pois, para maior percepção dos efeitos da TT U-E, especialmente de cultivares.

Palavras-chave: transferência de tecnologia. Universidades. capital humano técnico e científico.

\section{ABSTRACT}

The University-Enterprise Technology Transfer (U-ETT) is adopted as a strategy of open innovation. The Effective Contingent type is highlighted, as it allows the description of TTs and their effects on the human, scientific and technical capital. However, the cultivar, a TT with great social and economic value, is not mentioned in the model. This study investigated the effects of processes of E-U TT of cultivars on human, scientific and technical capital in Brazil and in the United States. The multi-case study was adopted with documentary research and interviews with agents (universities) and receivers (organizations) in the second semester of 2014 as well as the cross-analysis. The results show differences in innovation in the national contexts. The study of human, scientific and technical capital should extend to the creation of knowledge networks and the ability of communication between the academy and organizations, contributing to greater perception of the effects of E-U TT, especially of cultivars.

Keywords: technology transfer. Universities. scientific and technical human capital. 


\section{INTRODUÇÃO}

A busca do conhecimento por parte das organizações em instituições de pesquisa ou universidades tem sido crescentemente enfatizada como objeto de estudo e na prática, no desenvolvimento de inovações que beneficiem ambos e a sociedade. A importância de interações entre universidade e empresas para a inovação está presente no surgimento de conceitos sistematizados como os de Sistema Nacional de Inovação (SNI) (FREEMAN, 1995; LUNDVALL, 1992), modelo da Triple Helix (ETZKOWITZ, 2011; ETZKOWITZ; LEYDESDORFF, 2000; ETZKOWITZ, 2002), inovação aberta (CHESBROUGH, 2003) e têm promovido, ao longo dos anos, a transferência de tecnologia entre universidade e empresa (TT U-E).

Entende-se a TT U-E como a passagem de conhecimentos gerados pela universidade a empresas que proporciona inovação e maior capacidade tecnológica (CLOSS; FERREIRA, 2012) e se firma como estratégia de desenvolvimento tecnológico e econômico no alcance de diferencial competitivo no mercado.

Contudo, no Brasil, em comparação com países mais desenvolvidos, como os EUA, tal prática é considerada recente, o que se verifica em indicadores e leis específicas. Indicadores de inovação dos países, particularmente os voltados a esta interação como propulsora da inovação, apontam o Brasil em $54^{\circ}$ lugar dentre 144 países, em comparação com o $2^{\circ}$ dos EUA, conforme o World Economic Forum (WEF, 2015).

Como estímulos à TT U-E, no âmbito legal brasileiro destacam-se as Leis de Propriedade Intelectual, em 1996, a de Inovação, em 2004 (CORRÊA, 2007; GOMES et al. 2011) e a Lei ${ }^{\circ} 13.243$, de 11 de janeiro de 2016, que promoveu a atualização do marco legal da ciência, tecnologia e inovação (MDIC, 2017).

Enquanto que nos EUA, com notória antecipação, a Lei Bayh-Dole, em 1980 (MOWERY; SAMPAT, 2005; SIEGEL; WALDMAN; LINK, 2003; MOWERY et al., 2001; JENSEN; THURSBY, 2001; HENDERSON; JAFFE; TRAJTENBERG, 1998).

O resultado de fatores como a burocracia excessiva e os baixos investimentos para as pesquisas na maior parte das universidades brasileiras é o registro de poucas patentes, indicador comumente utilizado para medir o nível de inovação tecnológica, apesar da inovação se consolidar, efetivamente, quando inserida no mercado. As universidades brasileiras formam doutores, mas as pesquisas geram poucas patentes e inovação tecnológica (SENADO, 2012).

Dentre os benefícios da TT U-E na literatura estão os apresentados por Bozeman (2000) no 'Modelo de Eficácia Contingente de Transferência de Tecnologia', modelo expressivo nos estudos de TT U-E dada a grande quantidade de citações do seu artigo seminal em recente busca sobre o tema com a utilização do Web of Science. No modelo, por intermédio de critérios de eficácia, o autor faz alusão a benefícios da TT como os econômicos, os mercadológicos, os de custo de oportunidade, os políticos e os de capital humano técnico e científico. O autor também menciona objetos da TT U-E sem, contudo, incluir cultivar que, segundo o Ministério da Agricultura, Pecuária e Abastecimento brasileiro (MAPA, 2016), corresponde ao resultado de melhoramento em variedade de planta diferenciando a das demais em sua coloração, porte, resistência a doenças.

A cultivar, modalidade específica de propriedade intelectual, recentemente formalizada no Brasil (AVIANI, 2011), apresenta relevância social (ROCHA, 2011) e econômica pela possibilidade, segundo o United States Department of Agriculture - Agricultural Marketing Service (USDA, 2015), de maior produtividade agrícola, na melhor adaptação às mudanças climáticas e na maior efetividade no controle de pestes e de doenças, alinhando-se ao crescimento populacional mundial.

Bozeman, Dietz e Gaughan (1999), Rappa e Debackere (1992), Autio e Laamanen (1995), Lynn, Reddy e Aram (1996) e Bidault e Fischer (1994), Bozeman e Rogers (1998) destacam a importância de estudos sobre o capital humano técnico científico em TTs, um dos critérios de eficácia do modelo de Bozeman (2000), que, segundo o próprio autor, nem sempre enfatizado em pesquisas.

Desta maneira, buscou-se o estudo do capital humano técnico científico em TTs e, sabendo-se da lacuna na literatura de TT U-E com a aplicação do modelo de Bozeman em cultivares, a pesquisa ora apresentada envolveu cultivares, que passaram por processos de TTs bem sucedidos, em países com evidentes diferenças no desenvolvimento tecnológico (Brasil e EUA). 
Especialmente no intuito de contribuir para mais pesquisas com interesse no capital humano técnico e científico bem como de cultivares e, não obstante, para que processos futuros desta natureza sejam mais eficazes, a pesquisa concentrou-se no seguinte questionamento: como são os incrementos no capital humano técnico e científico para os agentes e os receptores de TT de cultivares em casos de Escolas de Agricultura universidades brasileira e norte-americana?

Sobre haver contribuição da TT para a maior capacidade técnica e ou científica, o artigo apresenta, com base no proposto por Bozeman (2000), a perspectiva não apenas dos agentes (que aqui contemplam universidades, mais precisamente Escolas de Agricultura) como se restringe o modelo do autor, mas também dos receptores de TT (organizações). Para Bozeman (2000), capital humano técnico trata da soma total de conhecimentos técnico e social e habilidades peculiares que um determinado indivíduo traz para o seu trabalho e os esforços de colaboração e refere-se aos incrementos na capacidade de executar e de fazer uso da pesquisa associados à TT.

As variáveis da categoria capital humano técnico e científico adotadas na pesquisa que se apresenta são as mesmas definidas por Bozeman (2000) e abrangem os efeitos da TT sobre (a) maior participação em redes de colaboração e em grupos de trabalho e mais pessoas disponíveis; (b) maior qualificação e (c) uma maior produção científica.

\section{BASE CONCEITUAL}

Aborda-se a relevância crescente das inovações, da TT-U-E e do desenvolvimento tecnológico relacionado à atividade agrícola, incluindo os contextos de inovação norte americano e brasileiro, além da caracterização do capital humano técnico e científico e a importância do estudo de cultivares.

\subsection{Evolução: contextos da inovação e TT U-E}

A interação entre universidades empresas e governo vem sendo crescentemente objeto de estudo. Na década de 1960, a criação do Triângulo de Sábato, indicou a necessidade de infraestrutura científico-tec- nológica robusta da transferência de resultados de pesquisas à estrutura produtiva e do aparato governamental com a liberação de recursos e com o poder de regulação (SÁBATO; BOTANA, 1968). A década de 1980 foi marcada com o surgimento do conceito de SNI, evidenciado especialmente por Freeman e Lundvall (ALBUQUERQUE, 2004), como síntese da elaboração neo-schumpeteriana, retratando o complexo arranjo institucional que, ao impulsionar o progresso tecnológico, é entendido como determinante da riqueza das nações. Na década de 1990, os SNIs destacaram-se em prol do desenvolvimento tecnológico, a partir da interação entre os seus agentes (universidades e institutos de pesquisa, governo e empresas) e da sua importância para uma empresa inovar (FREEMAN, 1995; LUNDVALL, 1992). Ainda nesta década, Etzkowitz e Leydesdorff criaram o modelo da Triple Helix, que incentiva a absorção de novas funções aos agentes e a criação de novas configurações - como incubadoras e Escritórios de Transferência de Tecnologia (ETTs) - e de leis e mecanismos de fomento, acrescentando às universidades uma 'terceira missão', que se relaciona aos processos de inovação e ao desenvolvimento econômico e social (VALENTE, 2010; ETZKOWITZ; LEYDESDORFF, 2000; ETZKOWITZ, 2002; ETZKOWITZ, 2011).

Fortaleceram-se então o conceito e a prática da inovação aberta, que ocorre quando as empresas passam a buscar a P\&D externamente (CHESBROUGH, 2003). Para Dalmarco, Zawislak e Karawejczyk (2012, p.4) a inovação aberta "pode ser considerada um requisito às relações descritas no triângulo de Sábato e Hélice Tripla" que estende, concomitantemente, uma estrutura na interação universidade-empresa que decorre, sobretudo, da existência de atores e canais.

Etzkowitz et al. (2000) assinalam o surgimento de uma terceira missão para as universidades, “a universidade empreendedora”, para além da missão de ensino e pesquisa. Com relação a essa tendência, os autores evidenciam como está o panorama de transição para mencionar que no continente europeu e na América Latina, as instituições acadêmicas, que eram controladas pelo Estado, vêm conseguindo autonomia. Os autores destacam a importância de que os governos continuem políticas que reforcem a interação entre U-E, para que o modelo de universidade empreendedora seja, de fato, uma realidade. 
Segundo Etzkowitz (2003), a inovação é cada vez mais baseada na 'Hélice Tripla' das interações indústria-governo-universidade. Modelos como o Triângulo de Sábato e da Hélice Tripla, e os estudos sobre os SNIs, vinculados à sua criação em diversos países, comprovam a importância atribuída às interações entre os seus elementos.

$\mathrm{Na}$ interação U-E, a TT U-E, compreendida como a passagem de conhecimentos gerados pela universidade a uma organização, permitindo inovar e ampliar a capacidade tecnológica (CLOSS; FERREIRA, 2012), é comumente adotada como estratégia de desenvolvimento tecnológico e econômico para competitividade.

No desenvolvimento da TT U-E no Brasil, a situação difere-se do contexto político-cultural norte-americano. No Brasil "as universidades não têm tradição no relacionamento com as empresas e não se preocupam em transferir os resultados das pesquisas para o setor privado, de forma a contribuir para a produção de inovações" (STAL; FUGINO, 2005, p. 11). Nos EUA há uma cultura de inovação e da cooperação U-E, sendo um grande marco para a TT U-E a sanção da Lei Bayh-Dole, em 1980 (MOWERY; SAMPAT, 2005; SIEGEL; WALDMAN; LINK, 2003; MOWERY et al., 2001; JENSEN; THURSBY, 2001; HENDERSON; JAFFE; TRAJTENBERG, 1998). No Brasil destacam-se leis criadas posteriormente, como a Lei da Propriedade Intelectual, em 1996, que possibilitou proteção tecnológica em áreas onde a pesquisa acadêmica do país já era forte, aumentando o interesse em patentes, e a Lei da Inovação, em 2004, que representou um marco a medidas de incentivo aos ambientes de inovação e a parcerias U-E, centros de pesquisa e governo (CORRÊA, 2007; GOMES et al., 2011).

Mais recentemente, a sanção da Lei no 13.243, de 11 de janeiro de 2016, permitiu a atualização do marco legal da ciência, tecnologia e inovação, com a concessão de maior autonomia para os Núcleos de Inovação Tecnológica (NITs), possibilidade de subvenção para bens de capital, aprimoramento de regras de propriedade intelectual, entre outras alterações positivas (MDIC, 2017).

\subsection{O Modelo de Bozeman e capital humano técnico e científico}

Entende-se, como destacam Garnica e Torkomian (2009), que a TT-U-E é um caminho alternativo e complementar para o alcance de um patamar tecnológico superior das empresas brasileiras. É necessário que tanto o poder público como universidades e empresas tenham conhecimento dos benefícios e das formas eficazes de atuação relacionadas à cooperação entre U-E, pois, como Closs e Ferreira (2012), a cooperação U-E gera inovações, aprendizados e benefícios mútuos e cria espaço para expandi-los.

Dentre os benefícios na literatura estão os apresentados por Bozeman (2000) no 'Modelo de Eficácia Contingente de Transferência de Tecnologia. Em pesquisa realizada no Web of Science sobre as publicações mais citadas do tema 'transferência de tecnologia' e 'universidade', na língua inglesa, o artigo em que o modelo é apresentado é um dos mais citados mundialmente.

Bozeman (2000) destaca inicialmente cinco dimensões principais que determinam as características da TT entre agentes (agências governamentais de pesquisa ou universidades) e receptores (empresas) - não inteiramente exaustivas, mas gerais suficientemente para incluir a maioria das variáveis examinadas em estudos sobre atividades de TT de universidades: (1) características do agente; (2) características do meio de transferência (por exemplo, cultivar); (3) características do objeto da transferência (o que é transferido); (4) ambiente da demanda (onde e porque ocorre a TT) e (5) características do receptor. Então, após tais definições, os efeitos da TT, por meio de categorias intituladas "critérios de eficácia" que podem abranger ambos agentes e receptores e, em determinadas variáveis, apenas um ou outro. Tais categorias critérios de eficácia de transferência de tecnologia são assim descritos: (1) out-the-door, que se refere a efetivação da TT, ou seja, à real transferência da tecnologia; (2) impacto no mercado, que envolve o seu impacto no aumento de receitas, criação de novos produtos etc.; (3) desenvolvimento econômico, que abrange o desenvolvimentos regional e/ou setor, com, por exemplo, geração de emprego e renda; (4) recompensa política, que trata do reconhecimento público vinculado à TT; (5) custo de oportunidade, 
que tange a compensação de ter realizado a TT em comparação com outras alternativas pré-existente; (6) capital humano técnico e científico, que abrange incrementos relativos às variáveis (a) participação em redes de colaboração e em grupos de trabalho e pessoas disponíveis; (b) maior qualificação e (c) uma maior produção científica.

A figura 1 sintetiza o Modelo de Eficácia Contingente de Transferência de Tecnologia de Bozeman (2000).

Figura 1 Modelo de Eficácia Contingente de Transferência de Tecnologia de Bozeman

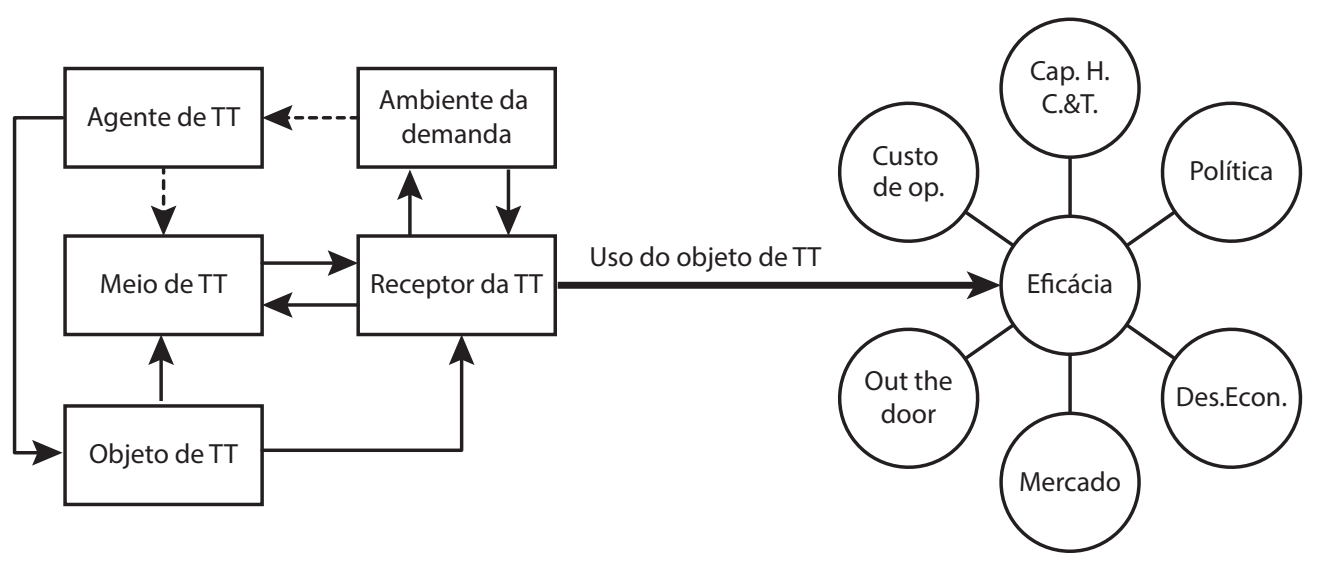

Fonte: adaptada de Bozeman (2000)

De acordo com Bozeman (2000), as linhas tracejadas representam ligações mais fracas entre os elementos do modelo.

Estudos realizados por Bozeman, Dietz e Gaughan (1999) evidenciaram que o capital humano técnico e científico é muitas vezes negligenciado nos critérios de eficácia de TT. Em complementação, os autores apontam que as avaliações de Pesquisa e Desenvolvimento $(\mathrm{P} \& \mathrm{D})$ raramente consideram o dinamismo das carreiras científicas e redes científicas e técnicas. Os mesmos autores assinalam ainda que na avaliação da política de Ciência e Tecnologia (C\&T) nos EUA destacam-se o uso de modelos microeconômicos e ferramentas correlatas, sobretudo as de custo-benefício que incluem resultados quantificáveis tais como número de artigos ou patentes produzidos em projetos de $\mathrm{P} \& \mathrm{D}$, de empregos criados por programas de TT e as contribuições de programas de desenvolvimento econômico de base tecnológica para as economias regionais. Bozeman (2000) acrescenta que capital humano técnico e científico é fonte de preocupação na prática e raramente tem sido foco de atenção em pesquisas sobre TT provenientes de institutos de pesquisa ou universidades.

Bozeman e Rogers (1998) sugerem também medidas relativas ao capital humano técnico e cien- tífico incorporadas a redes (valor de conhecimento coletivo) sobre como cientistas, técnicos e parceiros comerciais interagem. Bozeman, Dietz e Gaughan (1999), inclusive, propuseram um modelo alternativo para avaliação de projetos e programas de ciência e tecnologia, numa abordagem que denominaram de modelo técnico e científico do capital humano, que se concentra mais nas trajetórias de carreira dos cientistas e na capacidade em sustentarem-se e aprimorarem a sua capacitação.

Dentre os autores que enfatizam as redes relacionadas ao conhecimento, estão também, Rappa e Debackere (1992) e Autio e Laamanen (1995), que destacam a TT e seus impactos sobre as redes de conexões científicas e comerciais dos atores. Lynn, Reddy e Aram (1996) e Bidault e Fischer (1994) defendem veementemente as redes baseadas no conceito de eficácia, considerando que geralmente as relações na rede dos parceiros de tecnologia é mais importante do que os fatores de eficácia relativos ao mercado.

Malecki (1981a; 1981b) e Malecki e Tootle (1996) evidenciam ainda que a TT impulsiona a construção de capacidade numa determinada área geográfica, setor (campo) de estudos científicos e técnicos na instituição e que os incrementos para o 
capital humano técnico e científico habilitam o futuro desenvolvimento tecnológico e econômico.

Em seu modelo, Bozeman (2000) define o critério capital humano técnico e científico como os incrementos na capacidade de executar e de fazer uso da pesquisa associados à TT incluindo questionamentos como: 'a TT levou a incrementos na capacidade de executar e de fazer uso da pesquisa?'(contribuição para maior capacidade técnica e ou científica, por exemplo: com a participação em redes de colaboração, participação em grupos de trabalho, mais pessoas disponíveis, qualificação).

Para Bozeman (2000), capital humano técnico trata da soma total de conhecimentos técnico e social e habilidades peculiares que um determinado indivíduo traz para o seu trabalho e os esforços de colaboração e refere-se aos incrementos na capacidade de executar e de fazer uso da pesquisa associados à TT. Assim, as variáveis da categoria capital humano técnico e científico definidas por Bozeman (2000) e abrangem os efeitos da TT sobre (a) maior participação em redes de colaboração e em grupos de trabalho e mais pessoas disponíveis; (b) maior qualificação e (c) uma maior produção científica.

Quanto à (a) maior participação em redes de colaboração e em grupos de trabalho, consideram-se os incrementos associados a maior participação em grupos de trabalho que tenham potencial de desenvolvimento científico e ou tecnológico, em decorrência da TT, além da possibilidade da TT proporcionar maior contingente de pessoas disponíveis. Sobre (b) se a TT refletiu em maior qualificação para as pessoas que nela se envolveram. E, quanto à (c) se houve maior produção científica, especialmente artigos publicados e avanço tecnológico impulsionado por pesquisa científica decorrente ou em continuidade a partir da TT.

\subsection{TT de cultivares}

Segundo o representante no Brasil da Organização das Nações Unidas para Alimentação e Agricultura (FAO, 2014), a arrancada econômica dos países emergentes registrada na última década resultou em maior consumo de produtos da agropecuária. No Brasil, prevê-se aumento da demanda dos principais importadores de produtos agropecuários brasileiros até o ano de 2013, com destaque aos países economicamente emergentes, onde o consumo tem aumentado proporcionalmente mais que a população, como a China, que deve liderar as importações brasileiras de milho e soja (MAPA, 2013). Não apenas, portanto, o crescimento populacional, mas o aumento no consumo de alimentos eleva o valor da tecnologia e da sua contribuição para a maior produtividade do agronegócio, o que torna ainda mais relevantes estudos envolvendo cultivares.

Tanto no Brasil como nos EUA, há legislação específica para cultivares. O termo cultivar é originário da expressão em inglês cultivated variety e se refere a uma planta deliberadamente selecionada, com base em características específicas e almejadas do ponto de vista agronômico. No Brasil, a legislação específica e a estrutura para o registro de cultivares é recente, com a Lei de Proteção de Cultivares (LPC), Lei ${ }^{\circ}$ 9.456, de 25 de abril de 1997, sendo que proteção de variedades vegetais por meio de patentes foi descartada no Brasil, havendo a concessão de Certificado de Proteção de Cultivar para a proteção específica dos direitos relativos à propriedade intelectual (AVIANI, 2011; ROCHA, 2011). Nos EUA, conforme a sua Lei de Proteção de Cultivares, há três tipos de proteção de propriedade intelectual para os melhoristas obterem novas variedades de plantas que são: a proteção de cultivares (referente a sementes e tubérculos), as patentes de plantas (que se referem a plantas propagadas assexuadamente, excetuando-se os tubérculos) e as patentes de utilidade pública (para qualquer tipo de planta que apresente utilidade) (USDA, 2015).

Apesar dos avanços legais no âmbito de cultivares no Brasil, persiste a necessidade de aperfeiçoamentos nas limitações ao exercício efetivo dos direitos dos melhoristas (criadores das variedades). Com a LPC, o Brasil posicionou a agricultura no contexto da globalização por meio de intercâmbio tecnológico, legal e administrativo com os países membros da União Internacional para a Protecão das Obtenções Vegetais (International Union for the Protection of New Varieties of Plants - UPOV) e com diversos blocos de comércio (SANTOS et al., 2010). Os EUA são membros da UPOV desde 1981 e o Brasil desde 1999. Dados de contribuição com cultivares em relação aos países membros, atualizados em 2015, apresentam o 
Brasil com a metade do número de contribuições em relação aos EUA (UPOV, 2015).

No Brasil, portanto, o estudo específico de casos de TT de cultivares é proeminente pela sua recente formalização (AVIANI, 2011) e pelo pouco conhecimento sobre o papel desta modalidade de propriedade intelectual (ROCHA, 2011). Igualmente, por ser sabido que a recriação e o desenvolvimento de novas variedades e o melhoramento de variedades existentes proporcionam melhor adaptação às mudanças climáticas, um controle de pestes e de doenças mais efetivo, o que promove a produção agrícola e a segurança alimentar adaptadas ao aumento populacional (USDA, 2015). Constata-se que tanto nos EUA, como no Brasil, a proteção de cultivares é percebida por órgãos governamentais competentes como fundamental, pelo potencial de benefícios sociais e maior produtividade agrícola de alimentos de origem vegetal que podem gerar.

\section{MÉTODOS E TÉCNICAS}

A pesquisa caracterizou-se como pesquisa qualitativa e exploratória ao tratar de um estudo aprofundado, buscando familiarização e nova percepção do fenômeno, além da descoberta de novas ideias (EISENHARDT, 1989; MINAYO, 1994; BABBIE, 1998; FLIK, 2004). Trata-se de estudo de caso por se constituir numa pesquisa empírica com a investigação de "um fenômeno dentro de seu contexto da vida real, especialmente quando os limites entre o fenômeno e o contexto não estão claramente definidos" e propício para pesquisas cuja questão a ser respondida é sobre 'como' (YIN, 2001, p.32). Assim, optou-se pela estratégia de pesquisa multicasos, sendo um caso de TT com cultivar brasileiro e outro norte americano.

Os dados foram coletados com pesquisa documental e entrevistas semiestruturadas com agentes (universidades) e receptores (organizações) no segundo semestre de 2014.

Pesquisaram-se documentos públicos das instituições envolvidas - das universidades, tais como guias e cartilhas para as atividades de TT, estatísticas sobre as atividades de TT, Planejamento Estratégico (PE), política de inovação etc. e - das empresas - especialmente informações mais gerais, como histórico, áreas de atuação - nos negócios e geograficamente, que facilitaram na descrição dos receptores de tecnologia. Especialmente no caso norte-americanos também foram consultadas matérias veiculadas no site da própria universidade entre outras matérias veiculadas na mídia, pois se trata de caso de grande repercussão, e para complementar dados provenientes de entrevistas.

$\mathrm{Na}$ definição dos participantes, adotou-se a amostra não probabilística intencional (SELLTIZ; WRIGHTSMAN; COOK, 1974) com critérios pera a seleção das universidades, dos casos (processos de TT U-E) e dos informantes. A seleção das universidades obedeceu aos critérios excelência e a acessibilidade. A Universidade Brasileira (UB) foi selecionada pela acessibilidade à Escola de Agricultura (EA) e por ser a maior instituição pública universitária do país, reconhecida mundialmente pela excelência e, sobretudo, pela produtividade científica e tecnológica. Em estudo inicial e exploratório, foram realizadas visitas à EA da UB quando foram verificadas quais universidades norte-americanas com faculdades de agricultura bem sucedidas no processo de TT U-E e, em consulta a professores-pesquisadores, a Universidade Norte-Americana (UA) foi uma das instituições mencionadas e a qual, posteriormente, se obteve acesso para a realização da pesquisa in loco.

Os critérios na seleção dos processos de TT U-E na UA foram: envolver tecnologias desenvolvidas pelas Escolas ligadas à alimentação humana e cultivares, consideradas pelas instituições experiências de excelência, seguindo o que aconselha Creswel (2014), de que os casos selecionados devem merecer ser estudados. Nos EUA, o caso selecionado, advindo da área de melhoramento genético na horticultura, resultou ao numa cultivar batata doce. É considerado, pelo ETT, um dos três casos mais bem sucedidos de TT em retorno financeiro e em desenvolvimento econômico, especialmente por ser uma cultura de grande relevância econômica para o estado onde a universidade se encontra, elevando-se o, inclusive ao primeiro lugar na produção da cultura e na exportação, bem como pela grande parcela de substituição em relação às variedades antes cultivadas. No Brasil, a seleção dos casos obedeceu ao critério de semelhança na área de conhecimento (departamentos e formação dos pesquisadores envolvidos), de maneira a facilitar 
possíveis comparações. A TT selecionada foi desenvolvida no Programa de Genética e Melhoramento Vegetal, tratando-se de cultivar relativa ao gengibre com destacada importância econômica onde se encontram empresa receptora e seus produtores.

$\mathrm{Na}$ seleção dos informantes, a amostra formada por pessoas que participaram ativamente dos processos de TT U-E. Por parte dos 'agentes de TT' (universidades), foram selecionados os responsáveis pelos ETTs e pesquisadores envolvidos nos casos selecionados (dois no caso norte americano e três, incluindo um estudante, no caso brasileiro). Por parte dos 'receptores de TT' selecionaram-se dirigentes das organizações receptoras das TTs.

Inicialmente as entrevistas foram realizadas com os Dirigentes dos Escritórios de Transferência de Tecnologia (ETTs) para selecionar os casos e também indagar sobre questões formuladas a partir das categorias apresentadas no quadro 1, porém com questões um pouco mais brandas do que para os pesquisadores e receptores da TT. Entrevistas semi-estruturadas mais aprofundadas foram aplicadas junto aos principais pesquisadores responsáveis pelo desenvolvimento dos objetos transferidos, sendo dois de cada universidade e um dirigente, responsável pelo "recebimento" da tecnologia de cada organização envolvida. As entrevistas com os agentes (pesquisadores das universidades) englobaram questões relativas à procedência das pesquisas que geraram a TT, a caracterização dos seus grupos de trabalho e, especialmente, questões referentes às categorias do quadro 1. Com relação aos receptores (organizações), cada dirigente entrevistado respondeu sobre como se deu a aproximação com a academia e questões sobre o histórico e caracterização das mesmas, além de questões específicas sobre os efeitos da TT no capital humano técnico e científico baseadas nas categorias apresentadas no quadro 1.

Os dados das diferentes fontes foram organizados, seguindo o constructo da pesquisa nas categorias formadas a partir do critério de eficácia capital humano técnico e científico e triangulados, conforme as categorias apresentadas no quadro 1.

Quadro 1 Categorias e proposições

\begin{tabular}{c|l}
\hline \multicolumn{1}{c|}{ Efeito/Critério de Eficácia } & \multicolumn{1}{c}{ Categorias } \\
\hline Capital humano técnico e científico & $\begin{array}{l}\text { a Maior participação em redes de colaboração e em grupos de trabalho; } \\
\text { a Maior número de pessoas disponíveis; } \\
\text { a Maior qualificação; } \\
\text { a Produção científica (artigos) - apenas para os agentes }\end{array}$ \\
\hline
\end{tabular}

Fonte: elaborado pelos autores, com base nos autores supracitados

Creswel (2014) assevera que na análise nos casos múltiplos um formato típico é proceder primeiro uma descrição detalhada de cada caso, o que se denomina 'análise dentro de cada caso', seguida de uma análise temática entre os casos, que é a análise cruzada, além de realizar asserções ou interpretações do significado dos casos. Na análise conjunta, cruzada, verificaram-se a convergência e não convergência entre os casos, não se limitando, porém, às proposições pré-estabelecidas e procurando evidenciar o que é inerente a cada caso.

\section{ANÁLISE E DISCUSSÃO DOS RESULTADOS}

Apresentam-se a caracterização das universidades e dos casos e a especificação do capital humano técnico e científico nos casos brasileiro e norte americano.

\subsection{Caracterização das universidades e dos casos}

Ambas são universidades públicas e estaduais. A UA com 130 anos; mais de 200 cursos de graduação e de pós-graduação, com relevante contribuição ao desenvolvimento sócio econômico local e do país, 
destacando-se em inovação e a UB com 82 anos; com mais de 522 cursos de graduação e de pós-graduação, multicampi, com grande reconhecimento científico, sendo responsável por $22,4 \%$ de toda a produção científica do Brasil (LAFER, 2014), e melhor avaliada na área de inovação do Ranking Universitário da Folha (RUF, 2014). No Ranking Mundial Best Global Universities (US NEWS, 2015), a UA está em $212^{\circ}$ lugar e a UB em $117^{\circ}$ lugar.

A UA pode ser caracterizada como instituição 'land grant de economia do conhecimento', que passou de uma orientação primária voltada à agricultura para uma orientação voltada para a indústria (TORNATZKY; RIDEOUT, 2014). Já a UB nasceu com a clara missão de recolocar o estado de São Paulo na liderança econômica e política do país, e desde antes da sua criação, com as faculdades, vem respondendo com excelência às demandas da sociedade paulista e da sociedade brasileira (OLIVA, 2009).

A UA tem mais experiência em TT por fatores da sua microestrutura, por ser mais antiga e por ser uma land grant university, apresentando um parque tecnológico na sua estrutura e outro no seu entorno, mais antigos que o recente Parque Tecnológico no município onde está o Campus da EA UB, além da localização privilegiada numa região economicamente próspera. Indubitavelmente o SNI norte-americano, com as políticas nacionais de inovação e a eficiência e agilidade dos seus órgãos em processos de patenteamento, com as leis de inovação criadas anteriormente, além de mais voltada para a aplicabilidade e ganhos de ordem financeira, e da sua maior tradição na aproximação entre academia e empresas, torna os processos de TTs menos onerosos e mais desejáveis em comparação com o Brasil.

$\mathrm{O}$ caso norte americano configurou-se numa cultivar cuja licença foi não exclusiva e internacional, desenvolvendo-se a partir do Projeto de Melhoramento Participativo dos Produtores (Programa de Melhoramento de Batata-Doce da UA), sendo objeto de análise o processo de TT para a Comissão de Produtores de Batata Doce do Estado (receptor). Já o caso brasileiro configurou-se como cultivar com registro no MAPA, originada em projeto de pesquisa cujo foco foi o melhoramento participativo do gengibre, em que o receptor é uma micro empresa, estendendo-se a produtores da região.
Nos dois casos, coincidentemente, adotou-se a técnica do 'melhoramento participativo'. Segundo Machado (2014, p.35), "o melhoramento participativo é vinculado a questões sociais como a segurança alimentar e ambiental com a minimização de insumos químicos e ênfase aos sistemas agroecológico, elementos fundamentais à adoção de um modelo agrícola sustentável", que surge como alternativa e diferencia-se substancialmente do melhoramento genético convencional.

\subsection{Capital humano - técnico e científico: os casos da UA e da UB}

Apresentam-se os resultados da pesquisa e respectiva discussão sobre capital humano técnico e científico da TT de cultivares, obedecendo a sequência: na perspectiva dos agentes (universidades) e na perspectiva dos receptores de tecnologia (organizações receptoras).

Sobre (a) maior participação em redes de colaboração e em grupos de trabalho e o maior número de pessoas disponíveis para o agente, no caso norte americano, com a UA, ocorreu internamente à universidade ao se estreitaram os relacionamentos com colaboradores de várias áreas do conhecimento e com um técnico de laboratório e, externamente à universidade, com relações contínuas entre a diretora da Comissão e os produtores e com agentes de extensão do estado. Após a TT, o relacionamento se expandiu a outras empresas que buscam a Universidade e a Comissão visando novas tecnologias, especialmente da cultivar desenvolvida. A variedade (cultivar) fortaleceu o estado como grande produtor e referência na indústria de batata doce, aumentou a procura do agente e do receptor por outras instituições e produtores. No caso brasileiro houve maior interação com outras áreas do conhecimento e com outros grupos de pesquisa. A TT possibilitou, na percepção do agente UB, parceria com pesquisadora de importante Instituto Agronômico do país, além da interação com Associação dos Produtores de Gengibre da região do município e com o órgão de extensão agrícola estadual no município. Não houve, contudo, maior número de pessoas disponíveis.

No que se refere à (b) maior qualificação, foi notório, no caso norte americano, o aumento da qua- 
lificação para o agente, com maior know how em cada relação constituída na criação da variedade para o desenvolvimento de outras variedades, destacando-se o processo de coparticipação de produtores da Comissão com aprendizado mútuo. No caso brasileiro, conforme o agente, verificou-se maior qualificação com o melhoramento participativo: para a universidade, com o acesso ao conhecimento prático do agricultor e da empresa; e para a empresa e para os produtores o acesso ao conhecimento.

Nos dois casos houve (c) maior produção científica para os agentes, retratada no maior nú- mero de artigos científicos e, especialmente, no caso norte americano, artigos que são referência científica mundial na área. No caso brasileiro, a previsão é que a finalização do projeto de pesquisa surtirá em produção científica. Ademais, para ambos, respectivamente, o patenteamento e o registro da variedade, pontuam positivamente em seus currículos de pesquisadores.

O quadro 2 apresenta sucintamente as implicações da TT no que se refere à categoria capital humano técnico e científico, na percepção dos agentes.

Quadro 2 Capital humano técnico e científico dos agentes

\begin{tabular}{|c|c|c|}
\hline Variáveis & Caso Norte Americano & Caso Brasileiro \\
\hline $\begin{array}{l}\text { Maior participação em } \\
\text { redes de colaboração e em } \\
\text { grupos de trabalho }\end{array}$ & $\begin{array}{l}\text { Sim. Internamente: colaboradores de várias áreas do } \\
\text { conhecimento e do técnico de laboratório. Externa- } \\
\text { mente: comissão; agentes de extensão do Serviço } \\
\text { de Extensão do estado; com outras empresas e } \\
\text { produtores }\end{array}$ & $\begin{array}{l}\text { Sim. Outras áreas do conhecimento, grupos de } \\
\text { pesquisa, parceria com pesquisadora de Instituto } \\
\text { Agronômico e a interação com a Associação dos } \\
\text { Produtores de Gengibre da Região e com o órgão de } \\
\text { extensão agrícola estadual no município }\end{array}$ \\
\hline $\begin{array}{l}\text { Maior número de pessoas } \\
\text { disponíveis }\end{array}$ & Não & Não \\
\hline Maior qualificação & $\begin{array}{l}\text { Sim. Maior know how para o desenvolvimento de } \\
\text { outras variedades, aprendizado mútuo }\end{array}$ & $\begin{array}{l}\text { Sim. Maior qualificação mútua; Pesquisadora: apren- } \\
\text { dizado em técnicas de laboratório de melhoramento } \\
\text { clássico; várias áreas relacionadas na capacidade de } \\
\text { interação. Maior qualificação para a atividade docente } \\
\text { na parte prática do melhoramento participativo }\end{array}$ \\
\hline Produção científica & Sim & Ainda não \\
\hline
\end{tabular}

Fonte: dados primários

Na percepção do receptor, quanto à (a) maior participação em redes de colaboração e em grupos de trabalho, no caso norte americano confirmou-se na relação profícua e perene com a própria universidade e com seus pesquisadores, estreitando mais essa relação benéfica. No caso brasileiro, segundo o receptor, houve pela a própria interação com os atores do processo de TT que são, além da universidade, órgão de extensão governamental local e associação de produtores, além das perspectivas futuras advindas da maior abertura a parcerias, especialmente em estabelecimento de mais projetos coma própria universidade, envolvendo até mesmo outros departamentos e áreas do conhecimento.

Ainda em (a), quanto ao aumento no número de pessoas disponíveis para o receptor, no caso norte americano houve, limitando-se ao período do processo de TT, caracterizado pelo melhoramento participativo, além de incrementos com a contribuição dos pesquisadores da universidade e outros, com os quais a Comissão não teve contato direto. No caso brasileiro houve também aumento do número de pessoas com o próprio processo de criação da variedade e com o melhoramento participativo. Da mesma forma, limitando-se ao período de execução do projeto de pesquisa no desenvolvimento da cultivar.

No que se refere à (b) maior qualificação para o receptor, no caso norte americano aconteceu tanto especificamente da área do conhecimento (técnica) como na maior interação com os pesquisadores (habilidade de relacionamento com a academia). No caso brasileiro, o receptor se qualificou com o grande aprendizado para o produtor da empresa e para os demais produtores, estendendo-se à associa- 
ção, além de se prever um efeito multiplicador por parte dos produtores envolvidos nos momentos do melhoramento participativo para a capacitação de mais produtores da região.
O quadro 3 apresenta sucintamente as implicações da TT no capital humano técnico e científico na percepção dos receptores.

Quadro 3 Capital humano técnico e científico dos receptores

\begin{tabular}{l|l|l}
\multicolumn{1}{c|}{ Variáveis } & \multicolumn{1}{c|}{ Caso Norte Americano } & \multicolumn{1}{c}{ Caso Brasileiro } \\
\hline $\begin{array}{l}\text { Maior participação em } \\
\text { redes de colaboração e em } \\
\text { grupos de trabalho }\end{array}$ & $\begin{array}{l}\text { Sim. Com a própria universidade e com seus pesqui- } \\
\text { sadores, estreitando mais a relação }\end{array}$ & $\begin{array}{l}\text { Sim. Interação com os atores do processo de TT, além } \\
\text { das perspectivas para parcerias futuras, especialmente } \\
\text { com a universidade }\end{array}$ \\
\hline $\begin{array}{l}\text { Maior número de pessoas } \\
\text { disponíveis }\end{array}$ & Sim. Pesquisadores envolvidos diretamente e outros & $\begin{array}{l}\text { Sim. Especialmente no processo de criação da varie- } \\
\text { dade, com o melhoramento participativo }\end{array}$ \\
\hline Maior qualificação & $\begin{array}{l}\text { Sim. Na área do conhecimento (técnica) e na maior } \\
\text { interação }\end{array}$ & $\begin{array}{l}\text { Sim. Grande aprendizado para a empresa e produto- } \\
\text { res participantes, com previsão de'efeito multiplicador' }\end{array}$ \\
\hline
\end{tabular}

Fonte: dados primários

Sobre o pressuposto de Bozeman e Rogers (1998), sugerindo medidas incorporadas às redes (valor de conhecimento coletivo) sobre como os cientistas, os técnicos e os parceiros comerciais interagem: em nenhum dos casos observaram-se 'medidas' no que se refere à interação entre os atores das TTs. As universidades não se preocupam diretamente em mensurar e avaliar em curto e em longo prazo tais benefícios.

No que afirmam Lynn, Reddy e Aram (1996) e Bidault e Fischer (1994), de que as relações na rede dos parceiros de tecnologia são mais importantes do que os fatores de eficácia relativos ao mercado, possivelmente isso ocorre no caso norte americano, considerando que o conjunto de parcerias entre a UA e o receptor, em várias áreas do conhecimento relacionadas à batata doce, são entendidas como fundamentais, pois continuam e se reforçam ao longo do tempo, contribuindo para o destaque do estado no cultivo e no processamento da batata doce e no entendimento de que as parcerias são um meio para se conquistar mais mercados. Verifica-se uma especialização em batatas doces pela Comissão, com reforço contínuo do estado e da UA e sugere-se que a continuidade de relações em longo prazo e até mesmo o 'efeito multiplicador', sejam objeto de estudo. No caso brasileiro ainda não há evidências suficientes para confirmar ou refutar o pressuposto. Contudo, sugere-se estudos futuro, caso as parcerias
U-E se repitam continuamente como no caso norte americano.

Para Malecki (1981a; 1981b) e Malecki e Tootle (1996) em muitos casos, os decisores políticos e profissionais de TT são de opinião que a TT, a partir de projetos distintos, impulsione o desenvolvimento de capacidade dentro de uma área geográfica, de um setor (campo) de estudos científicos e técnicos; e os incrementos para o capital humano técnico e científico habilitam o futuro desenvolvimento tecnológico e econômico. No caso norte americano confirma-se a dedicação da Comissão e dos seus produtores, da UNA e do Estado, enquanto que, no caso brasileiro, com se trata de uma interação U-E muito recente, é cedo para ter tais evidências.

\section{CONSIDERAÇÕES FINAIS}

Com relação a estudos que adotam o modelo de Bozeman, a pesquisa relatada difere-se e contribui significativamente na aplicação do modelo pelos seguintes fatores: concentra-se em TT a partir de Escolas de Agricultura de Universidades Públicas e relacionada a alimentos; trata-se da aplicação, mesmo que de apenas um critério do modelo, objetivando a TT cultivares tanto formal como informal, o que não é citado no modelo como objeto; trata-se de estudo interinstitucional e internacional, considerando os 
aspectos do macrocontexto, especialmente as características dos SNI de cada país.

É fundamental a verificação de aspectos do macrocontexto considerando os possíveis reflexos na eficácia do processo de TT, especialmente ao se tratar de TTs advindas de agentes diferentes e de regiões também distintas, sobretudo de diferentes países. Considera-se, como foi aqui estudado, o conhecimento prévio das características dos SNIs.

Com relação aos aspectos peculiares dos Sistemas Nacionais de Inovação de cada país, tanto no Brasil, como nos EUA, buscou-se responder a questão da pesquisa: 'como são os incrementos no capital humano técnico e científico para os agentes e os receptores de TT de cultivares nos casos de Escolas de Agricultura universidades brasileira e norte americana?'. O problema foi investigado com base em estudo aprofundado e exaustivo dos casos de TT de cultivares de Escolas de Agricultura de Universidades Públicas e Estaduais, sendo um caso em cada país, ambos envolvendo a TT de cultivares.

Nos dois casos verificou-se que a capacidade técnico científica da academia foi fundamental para o desenvolvimento tecnológico, sem a qual seria impossível a descoberta ou atividade inventiva e a consequente inovação. A maior produção científica decorrente da TT foi claramente evidenciada no caso norte americano, enquanto que no brasileiro limitou-se a estimativas por se encontrar em estágio anterior.

Embora não tenha sido critério inicial para a seleção dos casos, os dois casos envolvendo melhoramento vegetal e cultivares, utilizaram-se coincidentemente de 'técnicas de melhoramento participativo', proporcionando a aproximação do agente e do receptor na concepção da tecnologia, tornando-a desde o início adaptada à necessidade do usuário, o receptor. Além de possibilitar essa agregação de valor, tal técnica permite a troca de experiência e de aprendizado mútuo: academia próxima da realidade das organizações e as organizações na proximidade com o aprendizado científico advindo da academia. $\mathrm{O}$ melhoramento participativo interfere positivamente na eficácia do processo no que se refere ao capital humano técnico e científico no resultado concreto da nova tecnologia, podendo ainda facilitar futuros processos de cooperação e de TT.
Entende-se que a capacidade de interação da academia com o meio empresarial e com a sociedade desenvolve-se nos processos de TT. Além disso, a técnica de melhoramento participativo para a criação de variedades e de melhoramento vegetal fortalece a capacidade de inter-relacionamento e não apenas da transferência de conhecimento numa única dimensão, mas, sobretudo na troca, com compartilhamento mútuo de conhecimento no desenvolvimento tecnológico.

Constatou-se ainda no caso norte americano que a vocação econômica do estado na cultura da batata doce, mais a especialização de diversas áreas do conhecimento da UA na cultura, com o suporte efetivo da administração do estado com suas estações experimentais integradas em projetos contínuos, forma base consistente e proveitosa e facilita as TTs e as inovações.

O caso brasileiro, apresentado como um segundo projeto de pesquisa da EA-UB na região, em continuidade a um projeto anterior, embora ainda prematuro se comparado com o projeto norte americano, possibilitou constatar seu potencial no capital humano técnico e científico. No passado a região foi exportadora do gengibre, produto de demanda crescente, mas sem oferta ocasionada pelos malefícios do fusário (doença que dizimou grande parte da cultura de gengibre na região). O projeto pode ser fortalecido pelo Estado, com políticas públicas federais ou estaduais, pela própria UB - como instituição pública -, bem como em decorrência de novos negócios a partir do gengibre.

Outro benefício evidenciado confere às universidades e às organizações receptoras, ganho de know how em comunicarem-se uma com a outra (partindo-se do pressuposto de que há diferenças no vocabulário entre ambos e alguns atritos na comunicação, considerando a primeira instituição com maior base científica e a segunda com a bagagem do mercado) e, vinculado a tais aptidões, a maior capacitação de ambas.

Evidências relevantes da pesquisa retratadas nos casos surtiram em propostas de aprimoramento do Modelo de Eficácia Contingente de Transferência de Tecnologia de Bozeman no processo de transferência de tecnologia a partir de Escolas de Agricultura de universidades brasileira e norte-americana para as 
empresas, no que tange ao critério capital humano técnico e científico.

Reside como contribuição essencial do estudo dos casos analisados, a incorporação de novas categorias a serem incluídas no critério de eficácia capital humano técnico e científico do modelo de Bozeman, não apenas para cultivares, mas que podem objeto de estudo extensivo a outros meios de TT como as patentes. Assim, propõe-se que tais categorias possam ser adotadas não apenas na aplicação do modelo em futuros estudos, mas na prática dos processos de TT, de maneira a geri-los com maior eficácia e a usufruir e a promover benefícios muitas vezes não esperados ou considerados. Uma síntese das categorias é apresentada no quadro 4 .

Quadro 4 Novas categorias de capital humano técnico e científico para o Modelo de Bozeman

\begin{tabular}{l|l}
\hline $\begin{array}{c}\text { Categorias para o Capital Humano Técnico e } \\
\text { Científico do Modelo de Bozeman }\end{array}$ & \multicolumn{1}{c}{$\begin{array}{c}\text { Especificação de Categorias a serem consideradas } \\
\text { a partir das Evidências do Presente Estudo }\end{array}$} \\
\hline $\begin{array}{l}\text { Capacidade de relacionamento interpessoal e de } \\
\text { aprendizado mútuo (agentes e receptores) }\end{array}$ & $\begin{array}{l}\text { As experiências de TT devem considerar não apenas a capacidade técnica e científica, } \\
\text { mas, adicionalmente, a de relacionamento interpessoal e de aprendizado mútuo, com } \\
\text { atenção para além da ação no sentido e agente - receptor }\end{array}$ \\
\hline $\begin{array}{l}\text { Verificação dos efeitos no capital humano técnico } \\
\text { e científico, em expansão posterior e em longo } \\
\text { prazo longo prazo) a partir da TT original }\end{array}$ & $\begin{array}{l}\text { Recomenda-se ainda estudos que abranjam efeitos no capital humano técnico e cientí- } \\
\text { fico com enfoque também na expansão posterior (em longo prazo) da TT original para } \\
\text { outras regiões, quando houver novas TTs nessas localidades para outras unidades organi- } \\
\text { zacionais e/ou com o envolvimento de universidades ou de institutos de pesquisa }\end{array}$ \\
\hline
\end{tabular}

Fonte: elaborado pelos autores, com base na pesquisa

Entende-se que as experiências de TT devem considerar não apenas a capacidade técnica e científica, mas, adicionalmente, a de relacionamento interpessoal e de aprendizado mútuo para o desenvolvimento tecnológico e para o êxito da inovação. Deve-se atentar para a TT de forma não limitada à ação agente - receptor, mas à troca de conhecimento mútuo entre as partes e à capacidade de interação interpessoal de dois mundos muitas vezes entendidos como distintos e separados. Depreende-se que quanto maior é a aproximação e a troca, maior é a possibilidade de ganhos diversos para ambos, incluindo-se a capacidade de relacionamento pessoal, ou a capacitação não apenas técnico-científica, mas de comunicação, dentre outros atributos. É a academia que sai dos muros da universidade e dispõe-se a aprender na troca, e mais 'qualificada', o que caracteriza uma relação que deve ser compreendida com enfoque interdisciplinar, também neste sentido.

Recomenda-se que os futuros estudos que abranjam efeitos no capital humano técnico e científico tenham também enfoque na expansão posterior (em longo prazo) da TT original para outras regiões por parte do receptor, como para outros países, conforme, o caso, desde que haja novas TTs nessas localidades provenientes de universidades ou de institutos de pesquisa.

Sugere-se, portanto, que tais categorias sejam consideradas em futuros estudos que tenham enfoque no Capital Humano Técnico e científico, seguindo o Modelo Bozeman os estudos sobre efeitos desta natureza, tão relevantes, para o desenvolvimento científico e tecnológico.

\section{REFERÊNCIAS}

ALBUQUERQUE, E. M. Ideias Fundadoras - apresentação: The 'National System of Innovation' in Historical Perspective: Christopher Freeman. Revista Brasileira de Inovação, v. 3, n. 1, p. 9-34, 2004.

AUTIO, E. ; LAAMANEN, T. Measurement and evaluation of technology-transfer - review of technology-transfer mechanisms and indicators. International Journal of Technology Management, v. 10, n. 7-8, p. 643-664, 1995. 
AVIANI, D. de M. A proteção de cultivares no contexto. In: Brasil. Ministério da Agricultura, Pecuária e Abastecimento. Proteção de Cultivares no Brasil. Secretaria de Desenvolvimento Agropecuário e Cooperativismo.Brasília: Mapa/ACS, 2011.

BABBIE, E. The practice of social research. Belmont: Wadsworth Publishing Company, 1998.

BIDAULT, F.; FISCHER, W.A. Technology transactions: networks over markets. R\&D Management, v. 24, n. 4, p. 373-386, 1994.

BOZEMAN, B. Technology transfer and public policy: a review of research and theory. Research Policy, v. 29, n. $4-5$, p. 627-655, 2000.

BOZEMAN, B. ROGERS, J. Knowledge value collectives: the proof of science is in the putting, Proceedings for the Conference on Laboratory Evaluation, Ecole des Mine, Paris, 1998.

BOZEMAN, B.;DIETZ, J. S.; GAUGHAN, M. Scientific and Technical Human Capital: An Alternative Model for Research Evaluation. International Journal of Technology Management, v. 22, n. 7-8, p. 716-740, 1999.

CHESBORUGH, H. W. Open innovation: the new imperative for creating and profiting from technology. Boston, Massachusetts. Harvard Business School Press, 2003.

CLOSS, L. Q.; FERREIRA, G. C. A transferência de tecnologia universidade-empresa no contexto brasileiro: uma revisão de estudos científicos publicados entre os anos 2005 e 2009. Gestão e Produção, v.19, n.2, p. 419-432. 2012.

CORREAA, F. A patente na universidade: contexto e perspectivas de uma política de geração de patentes na Universidade Federal Fluminense. 2007. Dissertação (Mestrado em Ciência da Informação). Universidade Federal Fluminense, Niterói, RJ, 2007.
CRESWEL, J. W. Investigação qualitativa \& projeto de pesquisa: escolhendo entre cinco abordagens. Porto Alegre: Penso, 2014.

DALMARCO, G.; ZAWISLAK, P.A. ; KARAWEJCZYK, T.C. Fluxo de Conhecimento na Interação Universidade-Empresa: uma abordagem complementar, Anais do 26 Encontro Nacional da Associação Nacional de Pós-Graduação e Pesquisa em Administração. Rio de Janeiro, 2012.

EISENHARDT, K. M. Building Theories from Case Study Research. Academy of Management Review. v. 14, n. 4 , p. 532-550, 1989.

ETZKOWITZ, H.; LEYDESDORFF, L. The dynamics of innovation: from National Systems and "Mode2" to a Triple Helix of university-industry-government relations. Research Policy, v. 29, n. 2, p. 109-123, 2000.

ETZKOWITZ, H. MIT and the Rise of Entrepreneurial Science. London: Routledge, 2002.

ETZKOWITZ, H. Research Groups As 'Quasi-Firms': The Invention of the Entrepreneurial University. Research Policy, v. 32, n. 1, p. 109-121, 2003.

ETZKOWITZ, H. The triple helix: science, technology and the entrepreneurial spirit. Journal of Knowledge-based Innovation in China, v. 3, n. 2, p. 76-90, 2011.

FAO. Food and Agriculture Organization of the United Nations. Organização das Nações Unidas para Alimentação e Agricultura -2014. Disponível em:<https://www.fao.org.br> Acesso em: 05 abr. 2015.

FLICK, U. Uma introdução à pesquisa qualitativa. Bookman, Porto Alegre, 2004.

FREEMAN, C. The "National System of Innovation" in historical perspective. Cambridge Journal of Economics, v. 19, n. 1, p. 5-24, 1995. 
GARNICA, L. A.; TORKOMIAN, A.L. V. (2009). Gestão de tecnologia em universidades: uma análise do patenteamento e dos fatores de dificuldade e de apoio à transferência de tecnologia no Estado de São Paulo. Gestão e Produção, v. 16, n. 4, p. 624-638, 2009.

GOMES, L. dos S. D. et al. Transferência de conhecimento e tecnologia da universidade para as empresas de base tecnológicas caracterizadas spin-off. Anais do I Congresso Brasileiro de Engenharia de Produção (ABEPRO). Ponta Grossa-PR, 2011.

HENDERSON, R.; JAFFE, A.; TRAJTENBERG, M. Universities as a source of commercial technology: a detailed analysis of university patenting, 1965-1988. The Review of Economic and Statistics, v.80, n.1, p. 119-127, 1998.

JENSEN, R.; THURSBY, M. Proofs and prototypes for sale: the licensing of university inventions. American Economic Review, v. 91, n.1, 240-259, 2001.

LAFER, C. Especial 80 anos USP. Pesquisa FAPESP, Ed. especial, 2014.

LUNDVALL, B. A. National systems of innovation: towards a theory of innovation and interactive learning. London: Pinter Publishers, 1992.

LYNN, L.H.; REDDY, N.M.; ARAM, J.D. Linking technology and institutions - the innovation community framework. Research Policy, v. 25, n.1, p. 91-106, 1996.

MACHADO, A. T. Construção histórica do melhoramento genético de plantas: do convencional ao participativo, Revista Brasileira de Agroecologia, v. 9, p.1, 35-50, 2014.

MALECKI, E. Government funded R\&D: some regional economic implications. The Professional Geographer, v.33, n.1, p. 72-82, 1981a.

MALECKI, E. Science technology and regional economic development: review and prospects. Research Policy, v.10, n. 4, p. 312-334, 1981 b.
MALECKI, E.; TOOTLE, D. The role of networks in small firm competitiveness. International Journal of Technology Management, v. 1, n. 1-2, p. 43-57, 1996.

MAPA. Ministério da Agricultura, Pecuária e Abastecimento. Projeções do agronegócio: Brasil 2012/2013 a 2022/2023, 2013. Ministério da Agricultura, Pecuária e Abastecimento. Assessoria de Gestão Estratégica. Brasília: Mapa/ACS.

MAPA. Ministério da Agricultura, Pecuária e Abastecimento. Ministério da Agricultura, Pecuária e Abastecimento. Cultivares Protegidas. Disponível em http://www.agricultura.gov.br/vegetal/registros-autorizacoes/protecao-cultivares/cultivares-protegidas Acesso em 18 jun. 2016.

MDIC. Ministério da Indústria, Comércio Exterior e Serviços Disponível em http://www.mdic.gov.br/ index.php/inovacao/fomento-a-inovacao/marco-legal-da-inovacao. Acesso em 27 fev. 2017.

MINAYO, M. C. de S. Pesquisa social: teoria, método e criatividade. Petrópolis -RJ: Vozes, 1994.

MOWERY D. C. et al. The growth of patenting and licensing by U.S. universities: an assessment of the effects of the Bayh-Dole act of 1980. Research Policy, v. 30, n. 1, p. 99-119, 2001.

ROMANO, Giovanni. Imagens da juventude na era moderna. In: LEVI,

MOWERY D.; SAMPAT, B. Universities in national innovation systems. In: Fargerberg, J.; Mowery, D.; Nelson, R. (Orgs.). The Oxford Handbook of Innovation. New York: Oxford University Press, 2005.

OLIVA, G. Modelo de Universidade, Missão e Visão de Futuro. In Vilela\& Lajolo (orgs.). USP 2034: Planejando o Futuro. São Paulo: Editora da Universidade de São Paulo, 2009.

RAPPA, M.A., DEBACKERE, K. Technological communities and the diffusion of knowledge. R\&D Management, v. 22, n. 3, p. 209-220, 1992. 
ROCHA, H. Apresentação. In: Ministério da Agricultura, Pecuária e Abastecimento. Proteção de Cultivares no Brasil. Brasília: MAPA/ACS, 2011.

RUF. Ranking Universitário Folha - 2014. Ranking de universidades. Folha de S. Paulo. Disponível em: $<$ http://ruf.folha.uol.com.br/2015/ranking-de-universidades/ranking-por-inovacao/> Acesso em: $22 \mathrm{dez} .2014$.

SÁBATO, J.; BOTANA, N. La ciência y La tecnologia en el futuro de América Latina. Revista de La integración, v. 1, n. 3, p. 15-36, 1968.

SANTOS, F. S. et al. Evolution, importance and evaluation of cultivar protection in Brazil: the work of the SNPC. Crop Breeding and Applied Biotechnology. S2: 99-110, 2012.

SELLTIZ, C.; WRIGHTSMAN, L. S. ; COOK, S. W. Métodos de pesquisa nas relações sociais. São Paulo: Ed. Pedagógica e Universitária Ltda, 1974.

SENADO. Universidades do Brasil: poucas patentes e inovação tecnológica, 2012. Disponível em: <http:// www.senado.gov.br/noticias/Jornal/emdiscussao/inovacao/universidades-brasil-doutores-pesquisas-patentes-inovacao-tecnologica.aspx > > . Acesso em: 15 mar. 2015.

SIEGEL, D. S.; WALDMAN, D.; LINK. A. (2003). Assessing the impact of organizational practices on the relative productivity of university technology transfer offices: an exploratory study. Research Policy. V. 32, n. 1, p. 27-48, 2003.

STAL, E.; FUJINO, A. As relações universidade-empresa no Brasil sob a ótica da Lei de Inovação. Revista de Administração e Inovação, v. 2, n. 1, 5-19, 2005.

TORNATZKY, L.G.; RIDEOUT, E.C. Innovation U 2.0 Reinventing University Roles in a Knowledge Economy, 2014. Disponível em: $<$ http://www.innovation-u.com/InnovU-2.0_rev-12-14-14.pdf > Acesso em: 15, set. 2015.
UPOV. International Union for the Protection of New Varieties of Plants. Members of the International Union for the Protection of New Varieties of Plants. International Convention for the Protection of New Varieties of Plants UPOV Convention (1961), as revised at Geneva (1972, 1978 and 1991), 2015. Disponível em:<http://www.upov.int/export/sites/upov/ members/en/pdf/pub423.pdf> Acesso em: 18, out. 2015.

US News. US News Education: Best Global Universities Rankings, 2015. Disponível em:<http://www.usnews. com/education/best-global-universities/rankings $>$ Acesso em: 10, mai. 2016.

USDA. United States Department of Agriculture. Agricultural Marketing Service. AMS, 2015. United States Department of Agriculture. Agricultural Marketing Service. Disponível em: $<$ http://www.ams. usda.gov/services/plant-variety-protection $>$ Acesso em: 12, out. 2015.

VALENTE, L. Hélice tríplice: metáfora dos anos 90 descreve bem o mais sustentável modelo de sistema de inovação. Entrevista Henry Etzkowitz: Conhecimento \& Inovação, v.6, n. 1, 2010. Disponível em: $<$ http://inovacao.scielo.br/scielo.php?script=sci_arttext\&pid=S1984-43952010000100002\&lng $=$ en\&nrm $=\mathrm{i}-$ sApanhado > Acesso em: 03, mar. 2013.

YIN, R. K. Estudo de caso. Planejamento e métodos. Porto Alegre: Bookman, 2001.

WEF. World Economic Forum. The Global Competitiveness Report 2014-2015,2015. Disponível em: <http://www.weforum.org/reports/global-competitiveness-report-2014-2015> Acesso em: 03, jul. 2015. 